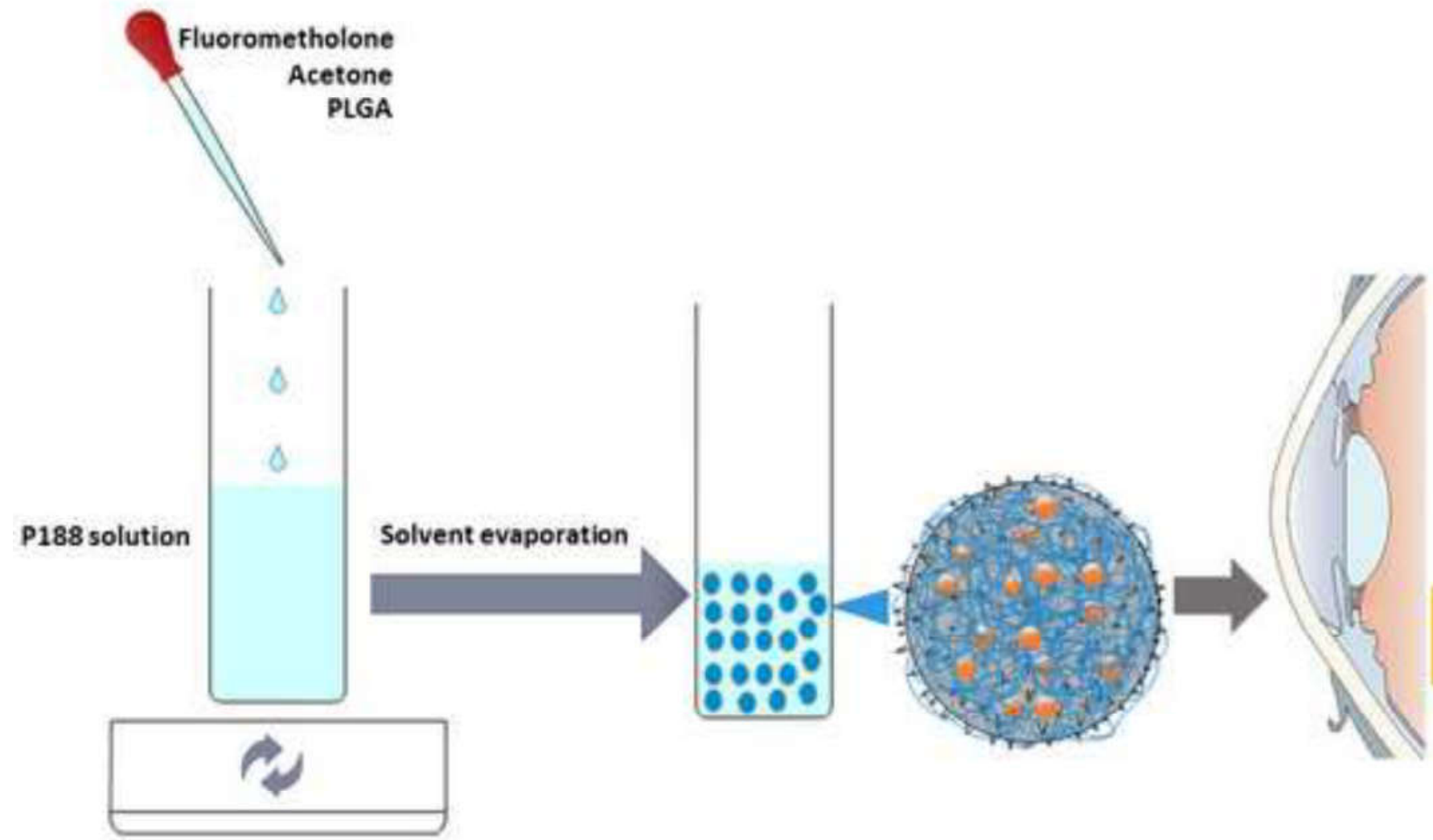

Ocular anti-inflammatory effect greater than the commercial formulation

Greater permeation in cornea 
TITLE

\section{Development of Fluorometholone-loaded PLGA Nanoparticles for Treatment of Inflammatory Disorders of Anterior and Posterior Segments of the Eye}

Roberto Gonzalez-Pizarro ${ }^{a, b}$, Marcelle Silva-Abreu ${ }^{a, b}$, Ana Cristina Calpena ${ }^{a, b}$, María Antonia $5 \quad$ Egea $^{\mathrm{a}, \mathrm{b}}$, Marta Espina ${ }^{\mathrm{a}, \mathrm{b}}$, María Luisa García ${ }^{\mathrm{a}, \mathrm{b}}$.

${ }^{a}$ Department of Pharmacy, Pharmaceutical Technology and Physical Chemistry, Faculty of Pharmacy and Food Sciences, University of Barcelona, 08028 Barcelona, Spain.

${ }^{\mathrm{b}}$ Institute of Nanoscience and Nanotechnology (IN2UB), University of Barcelona, Barcelona, Spain. 


\section{ABSTRACT}

The main objective of this study was the development and optimization of Fluorometholoneloaded PLGA nanoparticles for the treatment of inflammatory conditions of the eye. Design of experiments was used to obtain nanoparticles with the best physicochemical characteristics. The optimized nanoparticles containing $1.5 \mathrm{mg} \cdot \mathrm{mL}^{-1}$ of Fluorometholone showed a negative surface charge $(-30 \mathrm{mV})$ and an average size below $200 \mathrm{~nm}$ being suitable for ocular administration. Drug-polymer interaction studies confirmed no new bonds were formed during the synthesis. Nanoparticles performance was assessed with biopharmaceutical behavior studies, ocular tolerance, anti-inflammatory efficacy and bioavailability. The biopharmaceutical behavior of the drug from nanoparticles was adjusted to hyperbola order showing a significantly greater permeation in the cornea than in the sclera. The optimized formulation had significantly greater anti-inflammatory effects than the commercial formulation. In addition, nanoparticles increased drug penetration toward the vitreous. Polymeric nanoparticles of Fluorometholone could provide a suitable alternative for the treatment of inflammatory disorders of the anterior and posterior segments of the eye against of conventional topical formulations.

\section{KEY WORDS}

Fluorometholone; nanoparticles; permeation; ocular anti-inflammatory; PLGA; drug delivery. 


\section{Introduction}

The treatment of inflammatory eye diseases such as severe allergic conjunctivitis and uveitis is focused on the use of corticosteroids as anti-inflammatory drugs (Bielory et al., 2010). These ophthalmic drugs used topically have certain disadvantages ranging from the low amount of drug penetrating through the cornea to the limited residence time in the precorneal area. This causes that the suspensions need to be administered a greater many times per day to obtain a significant therapeutic effect (Gause et al., 2016). In other cases, in which the posterior segment is affected, as in posterior uveitis, intravitreal injections are used so that the drug can reach the target (Yasin et al., 2014). Moreover, the main ocular side effect after topical administration of corticosteroids include cataracts and increased intraocular pressure, which could induce visual disorders. Among all the corticosteroids, Fluorometholone (FMT) is characterized by a highest pharmacological potency for inflammations of the anterior segment of the eye with a significantly lower risk of increasing intraocular pressure (Chen et al., 2016; Shokoohi-Rad et al., 2017).

Currently, the encapsulation of drugs in polymer matrices has been one of the solutions for overcoming the disadvantages presented by ophthalmic suspensions (Danhier et al., 2012). Particularly, PLGA nanoparticles (NPS) have proven to be one of the most suitable topical ocular administration systems, due to their sustained and prolonged release of the drug, mainly produced by diffusion (Kapoor et al., 2015). Once the NPs have been administered, the PLGA hydrolyzes in monomers (lactic acid and glycolic acid) with subsequent metabolism in the Krebs cycle, which makes this polymer highly biodegradable and biocompatible (Anderson and Shive, 2012; Diebold and Calonge, 2010; Makadia and Siegel, 2011).

In other studies, it has been shown that PLGA NPs are able to cross the tear film and the cornea, with the possibility of reaching deeper tissues such as the vitreous and the retina (Silva-Abreu et al., 2018; Tahara et al., 2017). In different reports, PLGA has been shown to 
protect the drug from deactivation by the enzyme cytochrome P450 present in the tear film, corneal epithelium and ciliary, increasing the half-life of the drug (Guengerich, 2017). According to the above, these systems would allow to reduce the side effects associated with the drug with a sustained and safe release without the need for repeated administrations 75 (Siddique et al., 2015).

The main objective of this study was the development of FMT loaded-PLGA NPs (FMT-PLGANPs) able to reach tissues of the anterior and posterior segment of the eye with the aim to be administered less often than medications currently marketed. The physicochemical properties, drug-polymer interaction, short-term stability and in vitro/ex vivo biopharmaceutical behavior were also assayed. Ocular tolerance, in vivo anti-inflammatory efficacy and ocular bioavailability of FMT-PLGA-NPs were carried out as evidence of effectivity and usefulness of NPs as a novel treatment for ocular inflammatory disorders.

\section{Material and methods}

\subsection{Materials}

FMT was purchased from Capot Chemical (Hangzhou, China). PLGA RG 503H was obtained from Evonik Corporation (Birmingham, USA). Poloxamer 188 (P188) and Transcutol $^{\circledR}$ were given from BASF (Barcelona, Spain) and Gattefossé (Madrid, Spain), respectively. Acetone was purchased from Fisher Scientific (Pittsburgh, USA). Water through Millipore ${ }^{\circledR}$ MilliQ system was used for all the experiments and all the other reagents were of analytical grade.

\subsection{Preparation and optimization of NPs}

FMT-loaded PLGA NPs were prepared by solvent displacement method described elsewhere (Cañadas et al., 2016; Fessi et al., 1989). Briefly, PLGA (5.6-12.4 $\mathrm{mg} \cdot \mathrm{mL}^{-1}$ ) and the FMT (0.16$1.84 \mathrm{mg} \cdot \mathrm{mL}^{-1}$ ) were dissolved in $5 \mathrm{~mL}$ of acetone. This organic phase was added slowly dropwise, under moderate stirring, into $10 \mathrm{~mL}$ of an aqueous solution of P188 (1.6-18.4 $\mathrm{mg} \cdot \mathrm{mL}^{-1}$ ) adjusted to $\mathrm{pH}$ 7.4. The NPs resulting were stirred for $10 \mathrm{~min}$. After that, acetone was evaporated under reduced pressure. 
Design of experiments (DoE) was employed using central composite design matrix generated by StatGraphics Centurion XV. The central composite design was developed to analyze the effects of the independents variables on the dependents (Nekkanti et al., 2015). Three factors (concentration of surfactant [CP188], drug [CFMT] and polymer [CPLGA]), 3-level central composite design on the measured response (average particle size (Zav), polydispersity index $(\mathrm{PI})$, zeta potential (ZP) and entrapment efficiency (EE)) were established for this optimization procedure. Each factor was studied at five different levels coded (see Table I) and the responses were modelled through the full second-order polynomial equation:

$$
Y=\beta_{0}+\beta_{1} X_{1}+\beta_{2} X_{2}+\beta_{3} X_{3}+\beta_{11} X_{1}^{2}+\beta_{22} X_{2}^{2}+\beta_{33} X_{3}^{2}+\beta_{12} X_{1} X_{2}+\beta_{13} X_{1} X_{3}+
$$

$$
\beta_{23} X_{2} X_{3}
$$

where $Y$ is the measured response, $\beta_{0}$ to $\beta_{23}$ are the regression coefficients and $X_{1}, X_{2}$ and $X_{3}$ are the studied factors (Cano et al., 2018).

Table I: Variables and codes used in the experimental design.

\begin{tabular}{lccccc} 
& \multicolumn{5}{c}{ Levels } \\
\cline { 2 - 6 } Factor $\left(\mathrm{mg} \cdot \mathrm{mL}^{-1}\right)$ & -1.68 & -1 & 0 & +1 & +1.68 \\
\hline cFMT & 0.16 & 0.50 & 1.00 & 1.50 & 1.84 \\
CPLGA & 5.60 & 7.00 & 9.00 & 11.00 & 12.40 \\
CP188 & 1.60 & 5.00 & 10.00 & 15.00 & 18.40 \\
\hline
\end{tabular}

\subsection{Analysis of NPs}

Zav, $\mathrm{PI}$, and ZP of NPs were determined by dynamic light scattering (DLS) and electrophoretic mobility, respectively, in a Zetasizer NanoZS (Malvern Instruments, Malvern, UK). Samples were diluted (1:10) and the experiments were performed with disposable capillary cells DTS1070 (Malvern Instruments) at $25^{\circ} \mathrm{C}$. The reported values correspond to the mean \pm SD of three different batches of each NPs formulation.

The morphological examination of the NPs formulations was carried out by Transmission Electron Microscopy (TEM) on a Jeol model 1010. To visualize the NPs, copper grids carboncoated (carbon only) were activated with a glow discharge vacuum system. Samples (10 $\mu \mathrm{L})$ were placed on grids and negative staining performed with $2 \%$ uranyl acetate. 
120 The EE of FMT in the NPs was quantified indirectly by measuring the non-entrapped drug in the dispersion medium. The free FMT was separated by a filtration/centrifugation technique (1:10 dilution) by using an Amicon Ultracell-100 kDa (Amicon ${ }^{\circledR}$ Ultra; Millipore Corporation, Massachusetts, USA) centrifugal filter devices at $25^{\circ} \mathrm{C}$ and $5000 \mathrm{rpm}$ for $10 \mathrm{~min}$ (Heraeus, Multifuge 3 L-R, Centrifuge. Osterode, GER). The EE was calculated according to the following equation:

$$
\mathrm{EE}(\%)=\frac{c F M T_{0}-c F M T_{1}}{c F M T_{0}} \cdot 100
$$

where $\mathrm{CFMT}_{0}$ and $\mathrm{CFMT}_{1}$ are the total amount of FMT and free FMT in the supernatant, respectively. The samples were evaluated by a modified pharmacopeia method of RP-HPLC and validated according to the guidelines of the International Conference on Harmonization

130 (ICH, 2005; USP 29-NF 24, 2006). Briefly, samples were quantified using HPLC Waters 2695 separation module and a Kromasil ${ }^{\circledR} \mathrm{C} 18$ column $(5 \mu \mathrm{m}, 150 \times 4.6 \mathrm{~mm})$ with a mobile phase of methanol/water (65:35) at a flow rate of $1.0 \mathrm{~mL} \cdot \mathrm{min}^{-1}$. A diode array detector Waters ${ }^{\circledR} 2996$ at a wavelength of $239 \mathrm{~nm}$ was used to detect the FMT. A volume of $10 \mu \mathrm{L}$ of sample was injected. Data were processed using Empower $3^{\circledR}$ Software.

\subsection{Interaction studies}

\subsubsection{X-ray diffraction (XRD) analysis}

The state amorphous or crystalline of the drug in the NPs were determined by $\mathrm{x}$-ray spectral measurements using Siemens D500 system (Karlsruher, GER). X-ray powder diffractograms were recorded using a Cu K" radiation ( $45 \mathrm{kV}, 40 \mathrm{~mA}, \lambda=1.544 \AA$ ) in the range $(2 \theta)$ from $2^{\circ}$ to $60^{\circ}$ with a step size of $0.026^{\circ}$ and measuring time of $195.8 \mathrm{~s}$ per step.

\subsubsection{Fourier transform infrared (FTIR) analysis}

FTIR spectra of NPs and compounds separately were obtained using a Thermo Scientific Nicolet iZ10 with an ATR diamond and DTGS detector. The scanning range was $525-4000 \mathrm{~cm}^{-1}$.

\subsubsection{Differential scanning calorimetry (DSC) analysis}


Thermograms were obtained on a Mettler TA 4000 system (Greifensee, Switzerland) equipped with a DSC 25 cell. The temperature was calibrated by the melting transition point of indium prior to sample analysis. All samples were weighed (Mettler M3 Microbalance) directly in perforated aluminum pans (approximate weight of $2.5 \mathrm{mg}$ ), heated (under a nitrogen flow) at a rate of $2{ }^{\circ} \mathrm{C} \cdot \mathrm{min}^{-1}$ from $20^{\circ} \mathrm{C}$ to $120^{\circ} \mathrm{C}$ together to an empty pan used as a reference. Data were evaluated using the Mettler STARe V 9.01 DB software (Mettler-Toledo).

\subsection{Biopharmaceutical behavior}

\subsubsection{In vitro release study}

To identify the release profile of the FMT from the polymer matrix of NPs, a study was carried out in amber Franz cells (15 mm diameter). A dialysis membrane MW 12000-14000 Da 155 (Iberoamerica, Spain) was hydrated with the receptor medium methanol/water (65:35) for 24 h before mounted. The FMT-PLGA-NPs were compared with a commercial eye drops (Isoptoflucon ${ }^{\circledast}$ of $\left.1 \mathrm{mg} \cdot \mathrm{mL}^{-1}\right)$ and the free drug $\left(1 \mathrm{mg} \cdot \mathrm{mL}^{-1}\right)$ dissolved in phosphate buffer solution at $\mathrm{pH}$ 7.4. The sink conditions were sustained throughout the experiment for $46 \mathrm{~h}$ (Klose et al., 2011). A volume of $300 \mu \mathrm{L}$ of the samples was placed in the donor compartment and the receptor compartment was filled with receptor medium thermoregulated at $37^{\circ} \pm 0.5$ ${ }^{\circ} \mathrm{C}$ in continuous agitation. Samples of $300 \mu \mathrm{L}$ were withdrawn from the receptor compartment at fixed times and replaced by an equal volume of fresh receptor medium at the same temperature. The concentration of FMT released was measured by RP-HPLC. Values are reported as the mean \pm SD of the triplicates. Akaike's information criterion (AIC) and coefficient correlation $\left(r^{2}\right)$ were determined for each model as an indicator of the model's suitability (Ramos Yacasi et al., 2016).

\subsubsection{Ex vivo corneal and sclera permeation study}

The ex vivo FMT permeation from FMT-PLGA-NPs was evaluated using isolated pig cornea and sclera using Franz cells (9 $\mathrm{mm}$ diameter). Pig eyes (Landrace and Large White hybrid weighing 45-60 kg) were supplied from the Faculty of Medicine at Barcelona University, Spain. All 
experiments were developed following the Association for Research in Vision and Ophthalmology on the Use of Animals in Ophthalmic and Vision Research guidelines. These were approved by the Ethical Committee of the University of Barcelona (number 7428) and the Committee of Animal Experimentation of the Regional Autonomous Government of Catalonia, Spain (Law 32/2007 of November 7, 2007, and "Real Decreto 1201/2005", October 10, 2005). The pigs were sedated by intramuscular administration of ketamine $\left(3 \mathrm{mg} \cdot \mathrm{kg}^{-1}\right)$, xylazine $(2.5$ $\left.\mathrm{mg} \cdot \mathrm{kg}^{-1}\right)$ and midazolam $\left(0.17 \mathrm{mg} \cdot \mathrm{kg}^{-1}\right)$ and euthanized by an overdose of sodium thiopental $\left(100 \mathrm{mg} \cdot \mathrm{kg}^{-1}\right)$ under deep propofol anesthesia $\left(1 \mathrm{mg} \cdot \mathrm{kg}^{-1}\right)$. Eyes were removed and immediately excised. The cornea and sclera were fixed in Franz cells with a diffusion segment of $0.64 \mathrm{~cm}^{2}$. In all, $200 \mu \mathrm{L}$ of the test formulation (FMT-PLGA-NPs and Isoptoflucon ${ }^{\circledR}$ of $1 \mathrm{mg} \cdot \mathrm{mL}^{-1}$ ) were incubated in Franz cells and filled with Transcutol ${ }^{\circledR} \mathrm{P} /$ water $(65: 35)$. In all experiments, a constant temperature, thermoregulated with a water jacket of $32^{\circ} \pm 0.5^{\circ} \mathrm{C}$ and $37^{\circ} \pm 0.5^{\circ} \mathrm{C}$ was used for the cornea and sclera, respectively, with agitation at $600 \mathrm{rpm}$. Samples of $300 \mu \mathrm{L}$ were withdrawn from the receptor compartment at fixed times and replaced by an equal volume of fresh receptor medium at the same temperature. Sink conditions were maintained throughout the experiment.

To quantify the retained amount of drug $\left(Q_{R}\right)$ in the tissues tested, at the end of the permeation study, tissues were removed from each Franz cell. The cornea and sclera were cleaned using a $0.05 \%$ solution of sodium lauryl sulfate and washed with water. Afterward, the permeation segment of the tissues was excised, weighed and treated with methanol/water (65:35) under sonication for $15 \mathrm{~min}$. FMT concentration was quantified using Triple Quadrupole LC/MS/MS Mass Spectrometer (Perkin-Elmer AB Sciex Instruments) in MRM (multiple reaction monitoring). The separate module was HPLC Agilent 1200 series equipped with an atmospheric pressure electrospray ionization ion source. The separation of the drug was carried out on reverse phase column (Kromasi ${ }^{\circledR} \mathrm{C} 18$ of $5 \mu \mathrm{m}, 150 \times 4.6 \mathrm{~mm}$ ) using a mobile phase composed of methanol/0.1\% formic acid in water (65:35) at a flow rate of 0.6 
$\mathrm{mL} \cdot \mathrm{min}^{-1}$. Mass variation was recorded at 321.4 and $279.2 \mathrm{Da}$. Values were reported as the mean $\pm S D$. All the experiments were performed by triplicate.

Permeation parameters were calculated by plotting the cumulative FMT permeating versus time, determining $x$-intercept by linear regression analysis. The permeability coefficient $\left(K_{p}\right)$ $\left(\mathrm{cm} \cdot \mathrm{h}^{-1}\right)$, steady-state flux $(\mathrm{J})\left(\mathrm{ng} \cdot \mathrm{h}^{-1} \cdot \mathrm{cm}^{-2}\right)$ and amount of permeated at $24 \mathrm{~h}\left(\mathrm{Q}_{24}\right)(\mu \mathrm{g})$ were calculated (Carvajal-Vidal et al., 2017).

\subsection{Stability analysis of NPs}

The physical stability of the NPs at $4{ }^{\circ} \mathrm{C}$ and $25{ }^{\circ} \mathrm{C}$ were evaluated by Static Multiple Light Scattering technology (S-MLS) using Turbiscan ${ }^{\circledast}$ Lab. S-MLS identifies the different destabilization phenomena of the colloidal suspension such as creaming, sedimentation, flocculation, and coalescence. NPs were placed in a cylindrical glass measuring cell that was scanned by a pulsed near-infrared light source $(\lambda=880 \mathrm{~nm})$ with two synchronous optical detectors (transmission and backscattering). Due to the opacity of the NPs formulation, only

210 the backscattering profiles were used to evaluate the physical stability. The backscattering data were recorded every $24 \mathrm{~h}$ at different times after preparation (1, 15 and 30 days).

\subsection{Ocular tolerance}

\subsubsection{In vitro ocular tolerance}

In vitro ocular tolerance was assessed using the HET-CAM $^{\circledR}$ test in order to ensure that the formulation of FMT-PLGA-NPs are not irritating when they are administered as eye-drops. Irritation, coagulation and hemorrhage phenomena were measured by applying $300 \mu \mathrm{L}$ of the formulation studied on chorioallantoic membrane of a fertilized chicken egg, monitoring it during the first $5 \mathrm{~min}$ after the application. This assay was conducted according to the guidelines of ICCVAM (The Interagency Coordinating Committee on the Validation of 220 Alternative Methods). The development of the test was carried out with 6 eggs for each formulation (FMT-PLGA-NPs and Isoptoflucon ${ }^{\circledR}$ ), 3 for controls positive ( $\mathrm{NaOH} 0.1 \mathrm{M}$ ) and 
negative $(0.9 \% \mathrm{NaCl})$. The ocular irritation index (OII) was calculated by the sum of the scores of each injury according to the following expression:

$$
\mathrm{OII}=\frac{(301-\mathrm{h}) \cdot 5}{300}+\frac{(301-\mathrm{v}) \cdot 7}{300}+\frac{(301-\mathrm{c}) \cdot 9}{300}
$$

where $h, v$ and $c$ are times (s) until the start of hemorrhage, vasoconstriction and coagulation, respectively. The formulations were classified according to the following: Oll $\leq 0.9$ nonirritating; $0.9<$ OII $\leq 4.9$ weakly irritating; $4.9<$ OII $\leq 8.9$ moderately irritating; $8.9<$ OII $\leq 21$ irritating (ICCVAM, 2010).

\subsubsection{In vivo ocular tolerance}

230 To corroborate the results obtained from the HEM-CAM ${ }^{\circledR}$ test, the formulations (FMT-PLGANPs and Isoptoflucon ${ }^{\circledast}$ ) were evaluated using primary eye irritation test of Draize (SánchezLópez et al., 2016). For this case, pig eyes (Landrace and Large White) were used, where $50 \mu \mathrm{L}$ of each sample were instilled in the eye conjunctival sac ( $n=6 /$ group) and a gentle massage was applied to ensure circulation of the sample through the eyeball. Possible signs of irritation were observed at the time of instillation and after $1 \mathrm{~h}$ of exposure using the untreated contralateral eye as a negative control. Score Draize was determined by direct observation of the anterior segment of the eye and changes in ocular structures involving the cornea (turbidity or opacity), iris and conjunctiva (congestion, chemosis, swelling, and discharge) using Table S.3b Supplementary Material.

\subsection{Anti-inflammatory efficacy}

The induction of inflammation with the objective of evaluating the anti-inflammatory effect of FMT-PLGA-NPs compared to the commercial drug (Isopotoflucon ${ }^{\circledR}$ ) and $0.9 \%$ control group ( $\mathrm{NaCl}$ ), was carried out using pigs ( $n=6 /$ group). The study was conducted with the application of $50 \mu \mathrm{L}$ of $0.5 \%$ sodium arachidonate (SA) dissolved in PBS in the right eye, the left eye was used as control. After 30 minutes of exposure, $50 \mu \mathrm{L}$ of each formulation were instilled. 
Evaluation of inflammation was performed from the application of formulations up to $150 \mathrm{~min}$ according to Draize modified scoring system (Sánchez-López et al., 2016).

\subsection{Ocular bioavailability}

The amounts of drug that permeated from the formulation FMT-PLGA-NPs and Isopotoflucon ${ }^{\circledR}$ were evaluated $4 \mathrm{~h}$ after its application. To this end, $50 \mu \mathrm{L}$ of each formulation were administered to the pig's left eye. The amount of FMT retained from the different parts of the eye (sclera, cornea, aqueous and vitreous humor) was quantified by RP-HPLC.

\subsection{Statistical analysis}

The multiple comparisons were developed using one-way ANOVA with Tukey post hoc test with a significance of $\alpha<0.05$ after having confirmed the normality and equality of variances by Bartlett in the groups. All analyzed data were presented as mean \pm SD. GraphPad Prism ${ }^{\circledast}$ 6.01 software for windows was used to analyze the data.

\section{Results and discussions}

\subsection{Optimization of the FMT-PLGA-NPs}

According to the results obtained from the matrix central composite design (Table S.1 Supplementary Material) it was possible to statistically correlate the effects of the independent variables on Zav and EE $(p<0.05)$. In the first case, Zav was highly influenced by CPLGA and CP188 (Figure 1a). The study showed that as the amount of PLGA in the formulation increased, the NPs increased in size, the opposite happened when the concentration of cP188 increased. Zav's values (141.3-187.8 nm) were within the criteria of the ocular topical administration of nanostructured systems that would not cause irritation (Ali and Lehmussaari, 2006). In the second case, EE, mainly cFMT had a significantly positive effect (Figure 1b), where the ratio of drug concentration and EE is proportional, reaching values close to $100 \%$ (Table S.1 Supplementary Material). The latter could be associated with the fact that cFMT did not have a significant effect $(p=0.9818)$ on Zav (Figure S.1 Supplementary Material), which makes it clear that the load capacity of PLGA had not yet been reached. The other dependent 
variables $(\mathrm{PI}$ and $\mathrm{ZP})$ were not correlated with any independent variable $(p>0.05)$, however, the $\mathrm{PI}$ and $\mathrm{ZP}$ values concluded that all the formulations were monodisperse systems $(\mathrm{PI} \leq 0.1)$ and with a low probability that sedimentation would occur (Patel and Agrawal, 2011). Finally, according to the results of the evaluated parameters and their significant effects it was possible to select an optimized nanoparticle formulation (FMT-PLGA-NPs) containing 7.0 $\mathrm{mg} \cdot \mathrm{mL}^{-1}$ of PLGA, $15 \mathrm{mg} \cdot \mathrm{mL}^{-1}$ of $\mathrm{P} 188$ and $1.5 \mathrm{mg} \cdot \mathrm{mL}^{-1}$ of FMT. Stability studies, physicochemical interactions, release, permeation, eye tolerance, and anti-inflammatory efficacy were carried out to this optimized formulation.

\subsection{NPs physicochemical, morphological characterization and EE \%}

The optimized formulation showed a Zav of $149.1 \pm 3.5 \mathrm{~nm}$ and a PI of $0.079 \pm 0.008$, characteristic of monodisperse systems $(\mathrm{PI}<0.1)$, suitable for ocular administration due the fact that there will not be NP populations that have a size greater than $10 \mu \mathrm{m}$ that could cause ocular irritation associated with particle size (Ali and Lehmussaari, 2006). For the ZP, a negative value $(-34.3 \pm 1.6 \mathrm{mV})$ was obtained which was attributed to the PLGA polymer, specifically, to the terminal carboxylic groups of the polymer chain (Stolnik et al., 1995). The high PLGA entrapment capacity used in combination with high liposolubility of the FMT, explains the high value of $\mathrm{EE} \%(99.8 \pm 0.2 \%)$ in the optimized formulation. Finally, to corroborate the Zav data coming from the DLS technique, the FMT-PLGA-NPs were visualized by TEM (Figure 2). The TEM images showed that the NPs present similar values observed by DLS and without evidence of aggregation.

\subsection{Interaction studies}

To demonstrate the crystalline state of the components of the NPs and their interactions with each other, the XRD spectra of FMT-PLGA-NPs, PLGA, P188 and FMT were analyzed (Figure 3a). PLGA shows XRD profiles without any crystalline state signal. The semicrystalline profile of P188 showed peaks at $19.15^{\circ}$ and $23.43^{\circ}(2 \theta)$, which were not seen in the FMT-PLGA-NPs. In relation to FMT, it showed a crystalline profile with sharp and intense peaks at $10.38^{\circ}, 13.79^{\circ}$, 
$15.32^{\circ}, 16.32^{\circ}, 17.00^{\circ}, 17.60^{\circ}$ and $19.60^{\circ}(2 \theta)$. The previous peaks were evidenced in a low intensity in the profile of FMT-PLGA-NPs, due to the fact that FMT was dispersed in the polymer matrix both in crystalline state and molecular dispersion (Panyam et al., 2004).

FTIR analysis was performed to identify the interactions between FMT, P188 and PLGA. According to the analysis of the spectra of each of the components (Figure $3 \mathrm{~b}$ ), there was no evidence of the existence of a covalent bond between the elements that constituted the NPs. The IR spectrum of FMT showed several characteristic peaks, the first at a band of $3384 \mathrm{~cm}^{-1}$ given by the signal of the stretching vibration of $\mathrm{OH}$, some peaks from 2994 to $2876 \mathrm{~cm}^{-1}$ corresponding to the stretching vibration of $\mathrm{CH}$, some peaks at 1712 and $1654 \mathrm{~cm}^{-1}$ due to the stretching vibration the $\mathrm{C}=\mathrm{O}$, and finally, stretching vibration product of $\mathrm{C}=\mathrm{C}$ aromatic to the bands of 1612 and $1601 \mathrm{~cm}^{-1}$ (Rodrigues et al., 2009). In the case of the PLGA, it had a characteristic intense band at $1750 \mathrm{~cm}^{-1}$ corresponding to stretching vibration of the carbonyl 310 group. Small peaks corresponding to stretching vibration of the alkanes were displayed between the bands 2997 to $2882 \mathrm{~cm}^{-1}$. The stretching vibrations C-O and C-O-O were shown at the bands of 1166 and $1087 \mathrm{~cm}^{-1}$, respectively (Li et al., 2001). In the P188 showed two intense peaks, the first at $2881 \mathrm{~cm}^{-1}$ signal given by the stretching vibration of $\mathrm{CH}$ and the second at $1097 \mathrm{~cm}^{-1}$ corresponding to the stretching vibration of C-O (Yan et al., 2010). The FMT-PLGANPs showed comparable profile to PLGA with additional peaks of low intensity corresponding to $\mathrm{P} 188(\mathrm{C}-\mathrm{H})$ and to FMT (O-H, C-H and C=C).

The DSC thermograms of FMT, FMT-PLGA-NPs, P188 and PLGA are presented in the Figure 3c, in which it is possible to observe an acute peak belonging to the melting transition of P188 with a $\Delta \mathrm{H}=132.69 \mathrm{~J} \cdot \mathrm{g}^{-1}$ and a $\mathrm{T}_{\max }=54.24{ }^{\circ} \mathrm{C}$ (Yan et al., 2010). The FMT showed a melting transition characterized by a $\Delta \mathrm{H}=105.09 \mathrm{~J} \cdot \mathrm{g}^{-1}$ and with a $\mathrm{T}_{\max }=291.95{ }^{\circ} \mathrm{C}$ that was not present in the profiles of the NPs developed (data not shown) because the P188 has a flash point near $260{ }^{\circ} \mathrm{C}$. The PLGA showed the onset of the glass transition $\left(\mathrm{T}_{\mathrm{g}}\right)$ at $51.87^{\circ} \mathrm{C}$ and in the FMT- 
PLGA-NPs at $45.56{ }^{\circ} \mathrm{C}$, this decrease $T_{\mathrm{g}}$ is attributed to the drug-polymer interaction (Abrego et al., 2014; Sánchez-López et al., 2017).

\subsection{Biopharmaceutical behavior}

\subsubsection{In vitro release study}

The In vitro release study of FMT from FMT-PLGA-NPs compared to Isoptoflucon ${ }^{\circledR}$ and FreeFMT was carried out through Franz diffusion cells. In Figure 4, it is possible to observe that after $10 \mathrm{~h}$ the Free-FMT formulation released almost $100 \%$ of the FMT. In relation to the commercial solution (Isoptoflucon ${ }^{\circledR}$ ), after $24 \mathrm{~h}$ amount released was close to $100 \%$. All the above formulations were adjusted to a release profile of first order (Table II), which is characterized by a rapid release followed by a constant release (Fangueiro et al., 2016). FMTPLGA-NPs, had a release of $60 \%$ of the FMT, with continued increasing and sustained release of the drug, this system was adjusted to a profile of hyperbola order (Sánchez-López et al., 2017). The rapid release of the drug from NPs within the first $10 \mathrm{~h}$ was mainly due to the drug that is weakly bound to the most superficial areas of the polymeric matrix. In the sustained and increasing phase of the release of FMT, it could be due to a slow diffusion of the drug due to its affinity within the polymer matrix (Allahyari and Mohit, 2016; Anderson and Shive, 2012).

Table II: Parameters for kinetic models of FMT-PLGA-NPs, free drug solution and Isoptoflucon ${ }^{\circledR}$.

\begin{tabular}{lcccccc}
\hline & \multicolumn{2}{c}{ Isoptoflucon $^{\circledR}$} & \multicolumn{2}{c}{ Free FMT } & \multicolumn{2}{c}{ FMT-PLGA-NPs } \\
\hline Models & AIC & $\mathbf{R}^{\mathbf{2}}$ & AIC & $\mathbf{R}^{\mathbf{2}}$ & AIC & $\mathbf{R}^{\mathbf{2}}$ \\
\hline Zero Order & 117.49 & 0.62 & 119.75 & 0.45 & 107.51 & 0.66 \\
First Order & 88.29 & 0.97 & 68.70 & 0.99 & 74.45 & 0.98 \\
Higuchi & 109.21 & 0.81 & 113.11 & 0.68 & 97.56 & 0.85 \\
Hyperbola & 94.73 & 0.94 & 80.54 & 0.98 & 74.38 & 0.99 \\
Korsmeyer-Peppas & \multicolumn{2}{c}{$\mathrm{n}=0.052$} & $\mathrm{n}=0.030$ & $\mathrm{n}=0.033$ \\
& 106.73 & 0.85 & 103.98 & 0.85 & 91.85 & 0.91 \\
\hline
\end{tabular}

\subsubsection{Ex vivo corneal and sclera permeation study}

Studies of corneal and scleral permeation were carried out for $6 \mathrm{~h}$ (Figure 5). According to Table III, the release of the FMT-PLGA-NP drug is faster and penetrates more at the corneal 
level than at the scleral level $(p<0.001)$. In the different parameters of scleral permeation $(\mathrm{J}$, $K_{p}$ and $Q_{24}$ ) there were no significant differences between the formulations tested, except for the $Q_{R}$, where FMT-PLGA-NPs retain more drug $(p<0.01)$ than the Isoptoflucon ${ }^{\circledR}$. At corneal permeation level, it was observed that the formulation FMT-PLGA-NPs present significant differences in all parameters $(p<0.01)$ in contrast to the commercial formulation. Comparing the steady-state flux, the drug from the NPs permeated the cornea twice faster than Isoptoflucon ${ }^{\circledast}$. The previous relation was maintained for the parameters $K p$ and $Q_{24}$ at the corneal level. The $Q_{R}$ of FMT-PLGA-NPs was significantly lower in the cornea than the other formulation analyzed. According to the corneal permeation parameters, the NPs formulation has a greater capacity to cross the drug per unit of time (Carvajal-Vidal et al., 2017).

Table III: FMT sclera and corneal permeation parameters from FMT-PLGA-NPs and Isoptoflucon ${ }^{\circledast}$.

\begin{tabular}{lccccc}
\hline Tissue & Formulation & $\mathrm{J}\left(\mathbf{n g} \cdot \mathbf{h}^{-1} \cdot \mathrm{cm}^{-2}\right)$ & $\mathbf{K}_{\mathrm{p}}\left(\mathbf{c m} \cdot \mathbf{h}^{-1}\right) \cdot \mathbf{1 0}$ & $\mathbf{Q}_{\mathbf{2 4}}(\boldsymbol{\mu g})$ & $\mathbf{Q}_{\mathbf{R}}\left(\boldsymbol{\mu g} \cdot \mathbf{g}^{-1} \cdot \mathrm{cm}^{-2}\right)$ \\
\hline \multirow{2}{*}{ Sclera } & Isoptoflucon $^{\circledR}$ & $88.87 \pm 36.47$ & $5.92 \pm 2.43$ & $1.36 \pm 0.56$ & $3.26 \pm 0.27$ \\
& FMT-PLGA-NPS & $126.94 \pm 3.38$ & $8.43 \pm 0.23$ & $1.95 \pm 0.05$ & $5.07 \pm 0.06^{i}$ \\
\hline \multirow{2}{*}{ Cornea } & Isoptoflucon $^{\circledR}$ & $134.66 \pm 17.29$ & $8.98 \pm 1.15$ & $2.07 \pm 0.27$ & $7.01 \pm 0.16$ \\
& FMT-PLGA-NPs & $305.16 \pm 25.41^{\mathrm{ii}}$ & $20.34 \pm 1.69^{\mathrm{ii}}$ & $4.69 \pm 0.39^{\mathrm{ii}}$ & $2.73 \pm 0.30^{\mathrm{i}}$ \\
\hline
\end{tabular}

Letters represent statistical significance: ${ }^{i} p<0.01$ and "i $p<0.001$. J, steady-state flux; $K_{p}$, permeability coefficient; $Q_{24}$, permeated amount at $24 \mathrm{~h} ; \mathrm{Q}_{R}$, retained amount.

\subsection{Stability analysis of NPs}

In accordance with the Figure $6 \mathrm{a}$, it is possible to observe that the designed NPs present high stability after one month a storage temperature at $4{ }^{\circ} \mathrm{C}$. The previously described also happened with the NPs at a storage temperature at $25{ }^{\circ} \mathrm{C}$ until the course of 15 days (Figure $6 b$ ). This stability is associated with the high ZP of the NPs (approximately $-30 \mathrm{mV}$ ) that allow them to avoid flocculation and precipitation (Patel and Agrawal, 2011). After 30 days, the NPs stored at $25{ }^{\circ} \mathrm{C}$ begin to show signs of instability, due to the increase in temperaturedependent solubility of P188. This causes the release of P188 absorbed on the surface of the NP, gradually losing the ZP that causes the agglomeration and later, the flocculation of the nanostructured system (Fredenberg et al., 2011; Storm et al., 1995). 


\subsection{Ocular tolerance}

\subsubsection{In vitro ocular tolerance}

The HET-CAM was tested on optimized NPs compared to the commercial drug (Table S.2 Supplementary Material). For this, the assay was validated by evaluating a positive and negative control. The positive control, $0.1 \mathrm{M} \mathrm{NaOH}$, produced a severe hemorrhage (Figure S.2a Supplementary Material), classifying this solution as irritating. In contrast, the negative control did not produce any type of injury, categorizing it as nonirritating (Figure S.2b Supplementary Material). In relation to the formulation of FMT-PLGA-NPs and Isoptoflucon ${ }^{\circledast}$ showed a high ocular tolerance with an Oll $\leq 0.9$ during the whole experiment, classifying it as nonirritating (Figure S.2c and Figure S.2d Supplementary Material).

\subsubsection{In vivo ocular tolerance}

The topical administration in the eyes of the pigs showed no signs of irritation in the different structures (cornea, iris and conjunctiva) evaluated (Figure S.3 Supplementary Material). A value of OII = 0 was obtained both for the commercial formulation and for the optimized NPs, classifying them as nonirritating (Table S.3c Supplementary Material). These results agreed with the data obtained from the HET-CAM ${ }^{\circledR}$ assay and other studies (Abrego et al., 2015; Parra et al., 2016).

\subsection{Anti-inflammatory efficacy assay}

A study of anti-inflammatory efficacy was developed with the aim to determine the antiinflammatory capacity in contrast with a commercial formulation (Isoptoflucon ${ }^{\circledast}$ ) in an acute treatment. According to Figure 7, both the formulation Isoptoflucon ${ }^{\circledR}$ and the FMT-PLGA-NPs showed a significant anti-inflammatory effect from the first 30 minutes of exposure when compared with the positive control (SA). When comparing the anti-inflammatory effect between the formulations, it is evident that there is a significant difference $(p<0.01)$ of a greater anti-inflammatory effect of FMT-PLGA-NPs throughout the treatment. The above difference is explained by the information from the corneal permeation studies performed. 
The FMT-PLGA-NPs had a greater and faster permeation of the drug, reflecting a faster and more effective anti-inflammatory effect in contrast to Isoptoflucon ${ }^{\circledast}$. The nanostructured system gives the drug greater bioavailability at the corneal level and with the ability to reach deeper tissues such as vitreous and retina, making it useful for posterior uveitis (Bisht et al., 2017).

\subsection{Ocular bioavailability}

In order to determine the bioavailability of FMT in the different pig eye structures, the formulation of FMT-PLGA-NPs and Isoptoflucon ${ }^{\circledR}$ were instilled for an exposure period of $4 \mathrm{~h}$. The amount of FMT from FMT-PLGA-NPs in aqueous humor was $11.16 \pm 1.31 \mu \mathrm{g} \cdot \mathrm{mL}^{-1}$ significantly higher $(p<0.0001)$ to the other cavities. The amounts found in cornea, sclera and vitreous were $1.36 \pm 0.12 \mu \mathrm{g} \cdot \mathrm{mL}^{-1}, 0.82 \pm 0.09 \mu \mathrm{g} \cdot \mathrm{mL}^{-1}$ and $0.06 \pm 0.03 \mu \mathrm{g} \cdot \mathrm{mL}^{-1}$, respectively. The amount of drug found in the aqueous humor correlates with the data on permeation and anti-inflammatory efficacy. The ex vivo permeation study showed that the formulation FMTPLGA-NPs permeated greater amount of drug per unit of time with a lower retention than the other formulations tested, justifying that the NPs had a greater anti-inflammatory effect to the commercial formulation in the in vivo study. In this study, it was evidenced that the drug accumulates in the aqueous humor slowly releasing the drug to the deeper tissues such as the vitreous (Kalam and Alshamsan, 2017; Warsi et al., 2014). In the case of Isoptoflucon ${ }^{\circledR}$, no amounts of the drug were detected in any of the structures of the pig's eye with the quantification method used.

\section{CONCLUSIONS}

In the current study FMT-loaded PLGA NPs have been developed by solvent displacement technique, and in turn optimized using DoE, obtaining a formulation with physicochemical 420 (Zav, ZP, PI and EE) and morphological characteristics suitable for ocular administration. 
Through the Zav information delivered by the DLS and TEM technique (Zav $<200 \mathrm{~nm}$ ), the optimized formulation would not cause ocular irritation due to particle size. The formulation was submitted to the study of ocular tolerance in vitro and in vivo to argue the previously described, in which it was demonstrated that there is a high ocular tolerance of FMT-PLGANPs. The interaction studies showed that the drug is contained within the polymer matrix in the form of dispersion system and that the different components that make up the NPs do not have chemical interactions or strong covalent bonds that could affect pharmacology activity of FMT. The formulation FMT-PLGA-NPs shows a bimodal behavior in which the first $10 \mathrm{~h}$ presents a rapid release of the drug followed with increasing and sustained release of the drug. The permeation study allowed us to show that FMT-PLGA-NPs have a higher permeability at corneal level with a low corneal retention of the drug compared to the commercial formulation $(p<0.01)$. The low corneal permeation was corroborated by the bioavailability study, which showed that there is a greater amount of drug in the aqueous humor than in the other ocular structures, demonstrating that the system has the capacities to reach the vitreous. In the stability study of NPs, it is established that the system maintains its properties without signs of flocculation and/or sedimentation at a storage temperature of $4{ }^{\circ} \mathrm{C}$, at higher temperatures they could solubilize the P188 causing the loss of ZP causing the flocculation of the NPs. In the in vivo study of anti-inflammatory efficacy, the permeation and dialysis data were corroborated, in which it was evidenced that the FMT-PLGA-NPs have a greater anti-inflammatory effect than the commercial formulation during the whole experiment. Considering all the aspects analyzed, the formulation developed would be useful for the acute and chronic treatment of ocular inflammatory conditions with the ability to reach the posterior segment.

\section{ACKNOWLEDGMENTS}

445 The authors would like to thank to the Spanish Ministry of Science and Innovation (MAT201459134R) and to the National Commission for Scientific and Technological Research of Chile 
(CONICYT) 2014-72150367 for a doctoral grant (R.C.G.P). Thanks to Dr. Alvaro Gimeno and Lidia Gómez for their help in the in vivo studies.

\section{REFERENCES}

Abrego, G., Alvarado, H., Souto, E.B., Guevara, B., Bellowa, L.H., Parra, A., Calpena, A., Garcia, M.L., 2015. Biopharmaceutical profile of pranoprofen-loaded PLGA nanoparticles containing hydrogels for ocular administration. Eur. J. Pharm. Biopharm. 95, 261-70. https://doi.org/10.1016/j.ejpb.2015.01.026

Abrego, G., Alvarado, H.L., Egea, M.A., Gonzalez-Mira, E., Calpena, A.C., Garcia, M.L., 2014. Design of nanosuspensions and freeze-dried PLGA nanoparticles as a novel approach for ophthalmic delivery of pranoprofen. J. Pharm. Sci. 103, 3153-64. https://doi.org/10.1002/jps.24101

Ali, Y., Lehmussaari, K., 2006. Industrial perspective in ocular drug delivery. Adv. Drug Deliv. Rev. 58, 1258-1268. https://doi.org/10.1016/J.ADDR.2006.07.022

Allahyari, M., Mohit, E., 2016. Peptide/protein vaccine delivery system based on PLGA particles. Hum. Vaccin. Immunother. 12, 806-28. https://doi.org/10.1080/21645515.2015.1102804

Anderson, J.M., Shive, M.S., 2012. Biodegradation and biocompatibility of PLA and PLGA microspheres. Adv. Drug Deliv. Rev. 64, 72-82. https://doi.org/10.1016/j.addr.2012.09.004

Bielory, B.P., Perez, V.L., Bielory, L., 2010. Treatment of seasonal allergic conjunctivitis with ophthalmic corticosteroids: in search of the perfect ocular corticosteroids in the treatment of allergic conjunctivitis. Curr. Opin. Allergy Clin. Immunol. 10, 469-477. https://doi.org/10.1097/ACl.0b013e32833dfa28 
delivery: overcoming ocular barriers to treat posterior eye diseases. Wiley Interdiscip. Rev. Nanomedicine Nanobiotechnology e1473. https://doi.org/10.1002/wnan.1473

Cañadas, C., Alvarado, H., Calpena, A.C., Silva, A.M., Souto, E.B., García, M.L., Abrego, G., 2016. In vitro, ex vivo and in vivo characterization of PLGA nanoparticles loading pranoprofen for ocular administration. Int. J. Pharm. 511, 719-727.

https://doi.org/10.1016/j.ijpharm.2016.07.055

Cano, A., Ettcheto, M., Espina, M., Auladell, C., Calpena, A.C., Folch, J., Barenys, M., SánchezLópez, E., Camins, A., García, M.L., 2018. Epigallocatechin-3-gallate loaded PEGylatedPLGA nanoparticles: A new anti-seizure strategy for temporal lobe epilepsy. Nanomedicine Nanotechnology, Biol. Med. 14, 1073-1085. https://doi.org/10.1016/J.NANO.2018.01.019

Carvajal-Vidal, P., Mallandrich, M., García, M., Calpena, A., 2017. Effect of different skin penetration promoters in halobetasol propionate permeation and retention in human skin. Int. J. Mol. Sci. 18, 2475. https://doi.org/10.3390/ijms18112475

Chen, P.-Q., Han, X.-M., Zhu, Y.-N., Xu, J., 2016. Comparison of the anti-inflammatory effects of fluorometholone $0.1 \%$ combined with levofloxacin $0.5 \%$ and tobramycin/dexamethasone eye drops after cataract surgery. Int. J. Ophthalmol. 9, 1619-1623.

https://doi.org/10.18240/ijo.2016.11.13

Danhier, F., Ansorena, E., Silva, J.M., Coco, R., Le Breton, A., Préat, V., 2012. PLGA-based nanoparticles: an overview of biomedical applications. J. Control. Release 161, 505-22. https://doi.org/10.1016/j.jconrel.2012.01.043

Diebold, Y., Calonge, M., 2010. Applications of nanoparticles in ophthalmology. Prog. Retin. Eye Res. 29, 596-609. https://doi.org/10.1016/j.preteyeres.2010.08.002 Fangueiro, J.F., Calpena, A.C., Clares, B., Andreani, T., Egea, M.A., Veiga, F.J., Garcia, M.L., Silva, 
A.M., Souto, E.B., 2016. Biopharmaceutical evaluation of epigallocatechin gallate-loaded cationic lipid nanoparticles (EGCG-LNs): In vivo, in vitro and ex vivo studies. Int. J. Pharm. 502, 161-169. https://doi.org/10.1016/j.ijpharm.2016.02.039

Fessi, H., Puisieux, F., Devissaguet, J.P., Ammoury, N., Benita, S., 1989. Nanocapsule formation by interfacial polymer deposition following solvent displacement. Int. J. Pharm. 55, R1R4. https://doi.org/10.1016/0378-5173(89)90281-0

Fredenberg, S., Wahlgren, M., Reslow, M., Axelsson, A., 2011. The mechanisms of drug release in poly(lactic-co-glycolic acid)-based drug delivery systems-A review. Int. J. Pharm. 415, 34-52. https://doi.org/10.1016/J.IJPHARM.2011.05.049

Gause, S., Hsu, K.-H., Shafor, C., Dixon, P., Powell, K.C., Chauhan, A., 2016. Mechanistic modeling of ophthalmic drug delivery to the anterior chamber by eye drops and contact lenses. Adv. Colloid Interface Sci. 233, 139-154. https://doi.org/10.1016/J.CIS.2015.08.002

Guengerich, F.P., 2017. Intersection of the roles of cytochrome P450 enzymes with xenobiotic and endogenous substrates: relevance to toxicity and drug interactions. Chem. Res. Toxicol. 30, 2-12. https://doi.org/10.1021/acs.chemrestox.6b00226

ICCVAM, 2010. ICCVAM-recommended test method protocol: Hen's Egg test - chorioallantoic membrane (HET-CAM) test method. NIH Publ. N 10-7553 B29-B38.

ICH, 2005. International Conference on Harmonisation of technical requirements for registration of pharmaceuticals for human use (ICH), ICH Q2 (R1) Validation of Analytical Procedures: Text and Methodology.

Kalam, M.A., Alshamsan, A., 2017. Poly (d, I-lactide-co-glycolide) nanoparticles for sustained release of tacrolimus in rabbit eyes. Biomed. Pharmacother. 94, 402-411. https://doi.org/10.1016/J.BIOPHA.2017.07.110 
Kapoor, D.N., Bhatia, A., Kaur, R., Sharma, R., Kaur, G., Dhawan, S., 2015. PLGA: a unique polymer for drug delivery. Ther. Deliv. 6, 41-58. https://doi.org/10.4155/tde.14.91

Klose, D., Delplace, C., Siepmann, J., 2011. Unintended potential impact of perfect sink conditions on PLGA degradation in microparticles. Int. J. Pharm. 404, 75-82. https://doi.org/10.1016/J.IJPHARM.2010.10.054

Li, Y.-P., Pei, Y.-Y., Zhang, X.-Y., Gu, Z.-H., Zhou, Z.-H., Yuan, W.-F., Zhou, J.-J., Zhu, J.-H., Gao, X.J., 2001. PEGylated PLGA nanoparticles as protein carriers: synthesis, preparation and biodistribution in rats. J. Control. Release 71, 203-211. https://doi.org/10.1016/S01683659(01)00218-8

Makadia, H.K., Siegel, S.J., 2011. Poly Lactic-co-Glycolic Acid (PLGA) as biodegradable controlled drug delivery carrier. Polymers (Basel). 3, 1377-1397. https://doi.org/10.3390/polym3031377

Nekkanti, V., Marwah, A., Pillai, R., 2015. Media milling process optimization for manufacture of drug nanoparticles using design of experiments (DOE). Drug Dev. Ind. Pharm. 41, 124130. https://doi.org/10.3109/03639045.2013.850709

Panyam, J., William, D., Dash, A., Leslie-Pelecky, D., Labhasetwar, V., 2004. Solid-state solubility influences encapsulation and release of hydrophobic drugs from PLGA/PLA nanoparticles. J. Pharm. Sci. 93, 1804-1814. https://doi.org/10.1002/jps.20094

Parra, A., Clares, B., Rosselló, A., Garduño-Ramírez, M.L., Abrego, G., García, M.L., Calpena, A.C., 2016. Ex vivo permeation of carprofen from nanoparticles: a comprehensive study through human, porcine and bovine skin as anti-inflammatory agent. Int. J. Pharm. 501, 10-17. https://doi.org/10.1016/j.ijpharm.2016.01.056

Patel, V.R., Agrawal, Y.K., 2011. Nanosuspension: An approach to enhance solubility of drugs. J. Adv. Pharm. Technol. Res. 2, 81-7. https://doi.org/10.4103/2231-4040.82950 
Ramos Yacasi, G.R., García López, M.L., Espina García, M., Parra Coca, A., Calpena Campmany, A.C., 2016. Influence of freeze-drying and $\gamma$-irradiation in preclinical studies of flurbiprofen polymeric nanoparticles for ocular delivery using $d$-(+)-trehalose and polyethylene glycol. Int. J. Nanomedicine 11, 4093-106. https://doi.org/10.2147/IJN.S105606

Rodrigues, L.B., Leite, H.F., Yoshida, M.I., Saliba, J.B., Junior, A.S.C., Faraco, A.A.G., 2009. In vitro release and characterization of chitosan films as dexamethasone carrier. Int. J. Pharm. 368, 1-6. https://doi.org/10.1016/J.IJPHARM.2008.09.047

Sánchez-López, E., Egea, M.A., Cano, A., Espina, M., Calpena, A.C., Ettcheto, M., Camins, A., Souto, E.B., Silva, A.M., García, M.L., 2016. PEGylated PLGA nanospheres optimized by design of experiments for ocular administration of dexibuprofen -in vitro, ex vivo and in vivo characterization. Colloids Surfaces B Biointerfaces 145, 241-250. https://doi.org/10.1016/j.colsurfb.2016.04.054

Sánchez-López, E., Ettcheto, M., Egea, M.A., Espina, M., Calpena, A.C., Folch, J., Camins, A., García, M.L., 2017. New potential strategies for Alzheimer's disease prevention: pegylated biodegradable dexibuprofen nanospheres administration to APPswe/PS1dE9. Nanomedicine 13, 1171-1182. https://doi.org/10.1016/j.nano.2016.12.003 betamethasone, fluorometholone and loteprednol etabonate on intraocular pressure in patients after keratorefractive surgery. J. Curr. Ophthalmol. 1-6. https://doi.org/10.1016/J.JOCO.2017.11.008

Siddique, M.I., Katas, H., Iqbal Mohd Amin, M.C., Ng, S.-F., Zulfakar, M.H., Buang, F., Jamil, A., 2015. Minimization of local and systemic adverse effects of topical glucocorticoids by nanoencapsulation: in vivo safety of Hydrocortisone-Hydroxytyrosol loaded chitosan nanoparticles. J. Pharm. Sci. 104, 4276-86. https://doi.org/10.1002/jps.24666 
Silva-Abreu, M., Calpena, A.C., Espina, M., Silva, A.M., Gimeno, A., Egea, M.A., García, M.L., 2018. Optimization, biopharmaceutical profile and therapeutic efficacy of pioglitazoneloaded PLGA-PEG nanospheres as a novel strategy for ocular inflammatory disorders. Pharm. Res. 35, 11. https://doi.org/10.1007/s11095-017-2319-8

Stolnik, S., Garnett, M., Davies, M., Illum, L., Bousta, M., Vert, M., Davis, S., 1995. The colloidal properties of surfactant-free biodegradable nanospheres from poly $(\beta$-malic acid-cobenzyl malate)s and poly(lactic acid-co-glycolide). Colloids Surfaces A Physicochem. Eng. Asp. 97, 235-245. https://doi.org/10.1016/0927-7757(95)03081-N

Storm, G., Belliot, S.O., Daemen, T., Lasic, D.D., 1995. Surface modification of nanoparticles to oppose uptake by the mononuclear phagocyte system. Adv. Drug Deliv. Rev. 17, 31-48. https://doi.org/10.1016/0169-409X(95)00039-A

Tahara, K., Karasawa, K., Onodera, R., Takeuchi, H., 2017. Feasibility of drug delivery to the eye's posterior segment by topical instillation of PLGA nanoparticles. Asian J. Pharm. Sci. 12, 394-399. https://doi.org/10.1016/J.AJPS.2017.03.002

USP 29-NF 24, 2006. United States Pharmacopeia and National Formulary (USP 39-NF 34). United States Pharmacopeial Convention., Rockville, Md.

Warsi, M.H., Anwar, M., Garg, V., Jain, G.K., Talegaonkar, S., Ahmad, F.J., Khar, R.K., 2014. Dorzolamide-loaded PLGA/vitamin E TPGS nanoparticles for glaucoma therapy: Pharmacoscintigraphy study and evaluation of extended ocular hypotensive effect in rabbits. Colloids Surfaces B Biointerfaces 122, 423-431. https://doi.org/10.1016/j.colsurfb.2014.07.004

Yan, F., Zhang, C., Zheng, Y., Mei, L., Tang, L., Song, C., Sun, H., Huang, L., 2010. The effect of poloxamer 188 on nanoparticle morphology, size, cancer cell uptake, and cytotoxicity. Nanomedicine 6, 170-8. https://doi.org/10.1016/j.nano.2009.05.004 
Yasin, M.N., Svirskis, D., Seyfoddin, A., Rupenthal, I.D., 2014. Implants for drug delivery to the posterior segment of the eye: a focus on stimuli-responsive and tunable release systems.

J. Control. Release 196, 208-221. https://doi.org/10.1016/j.jconrel.2014.09.030 


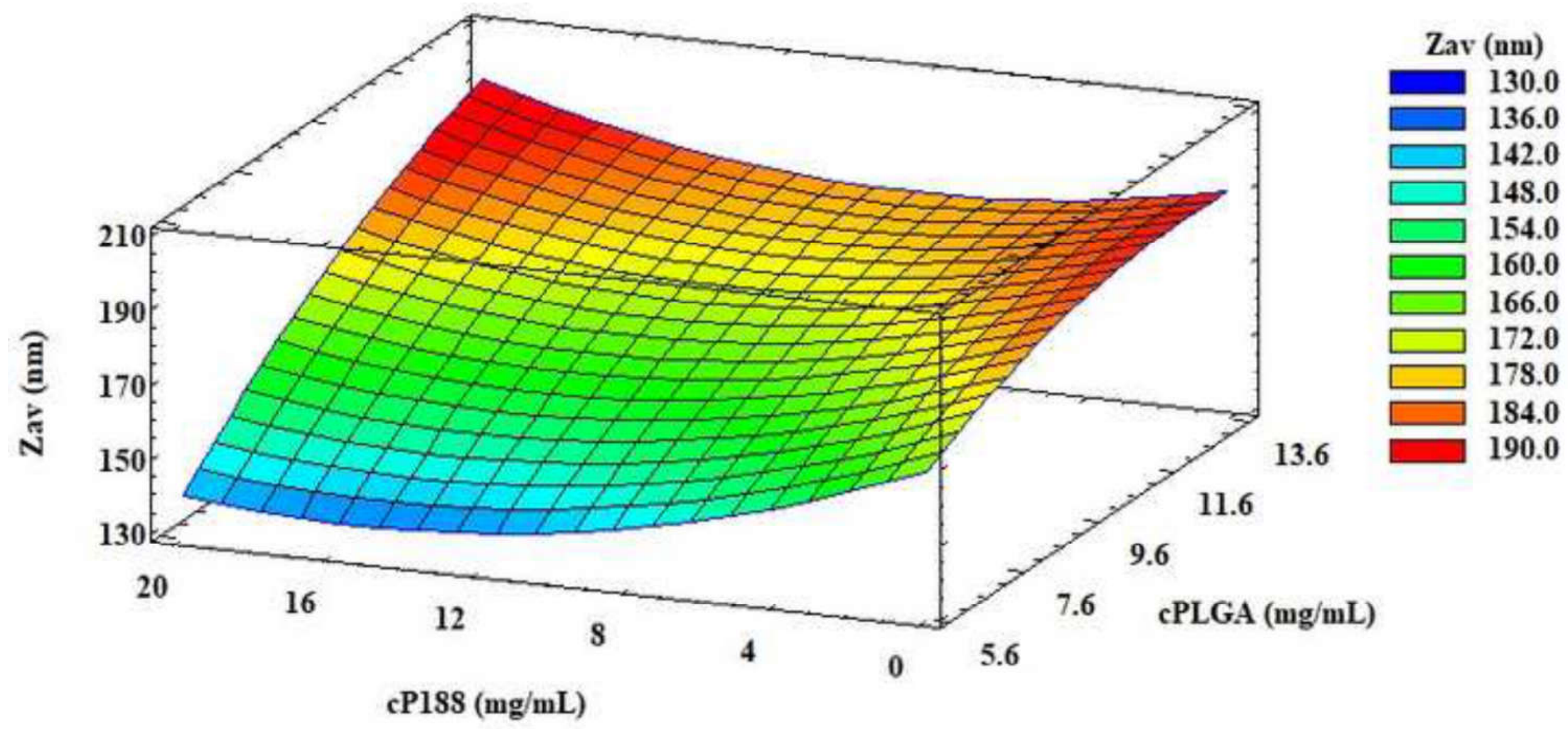




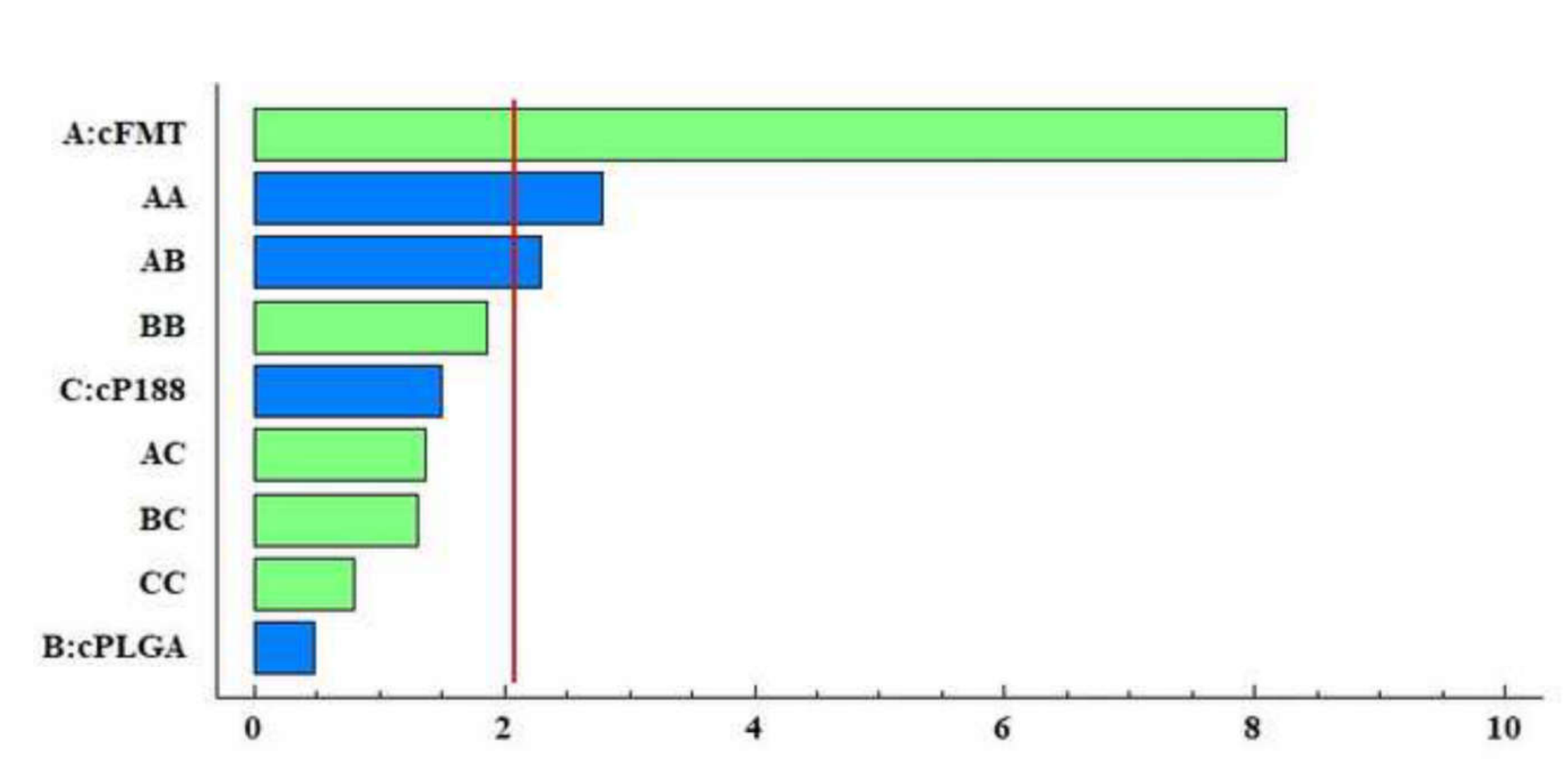




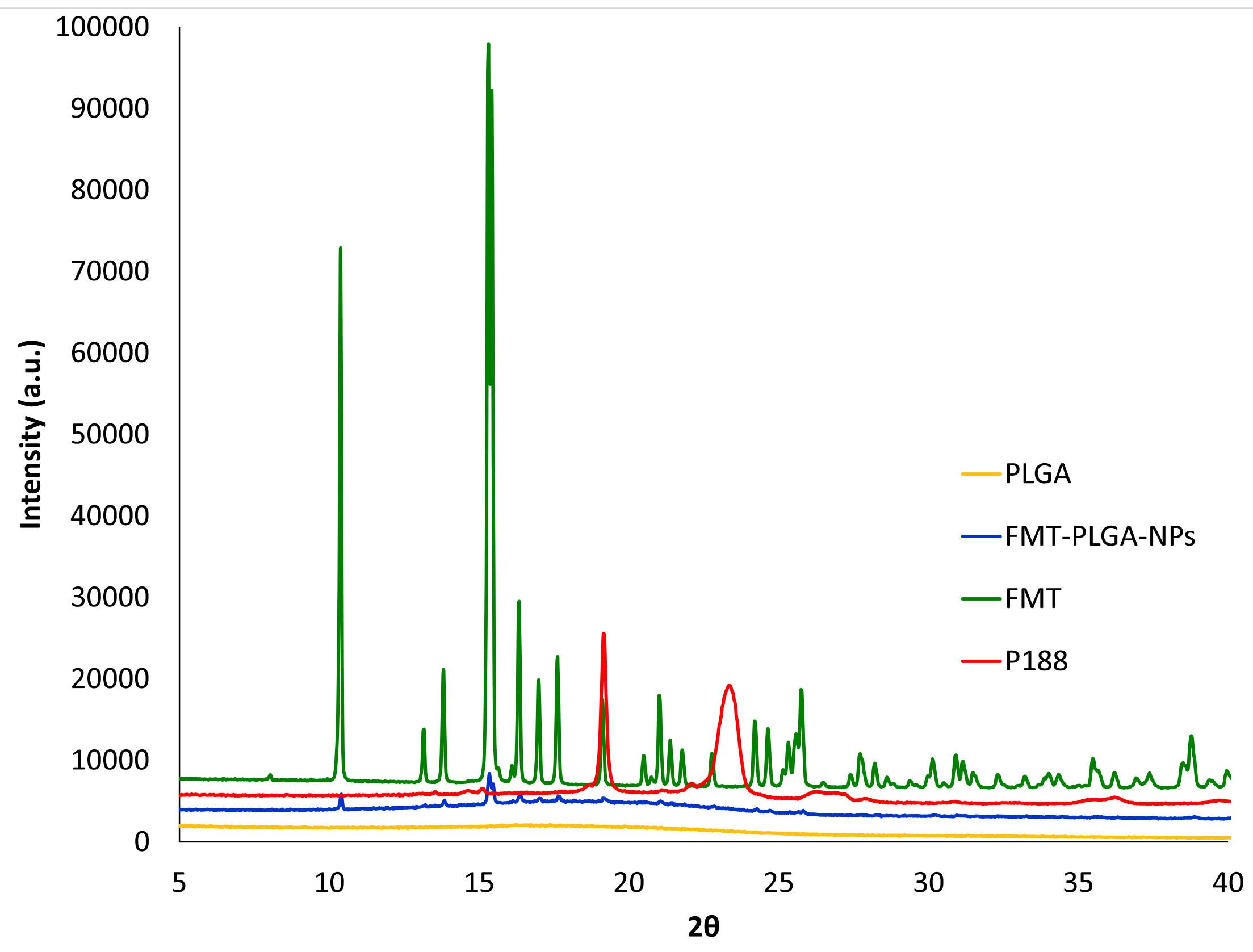




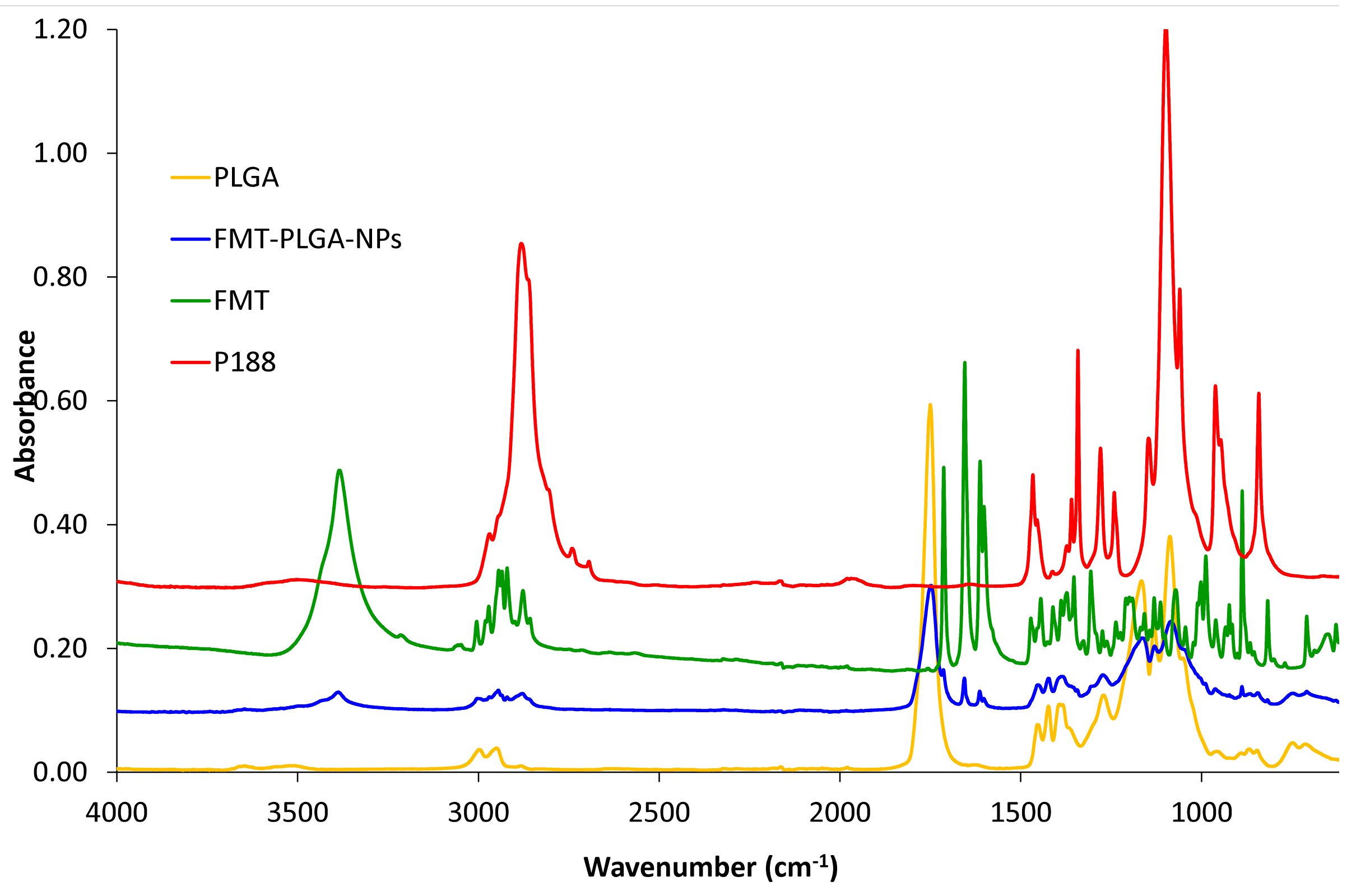




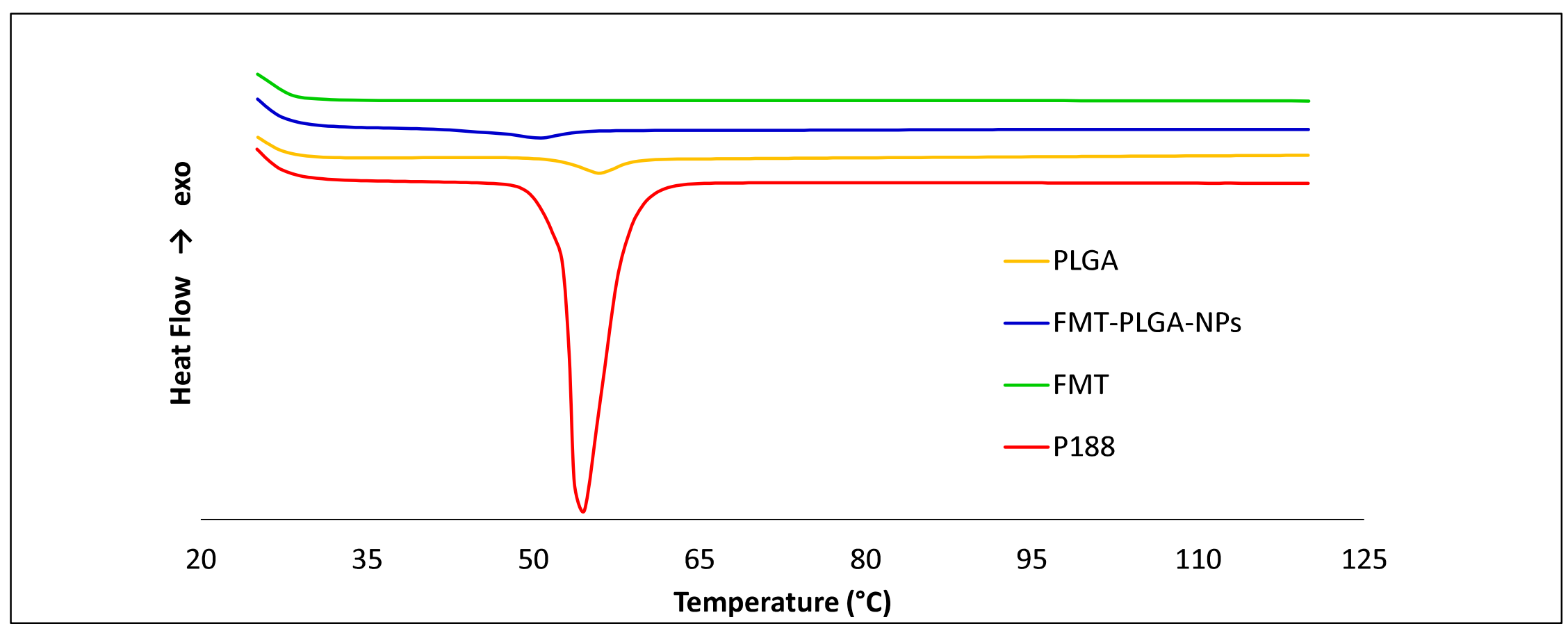




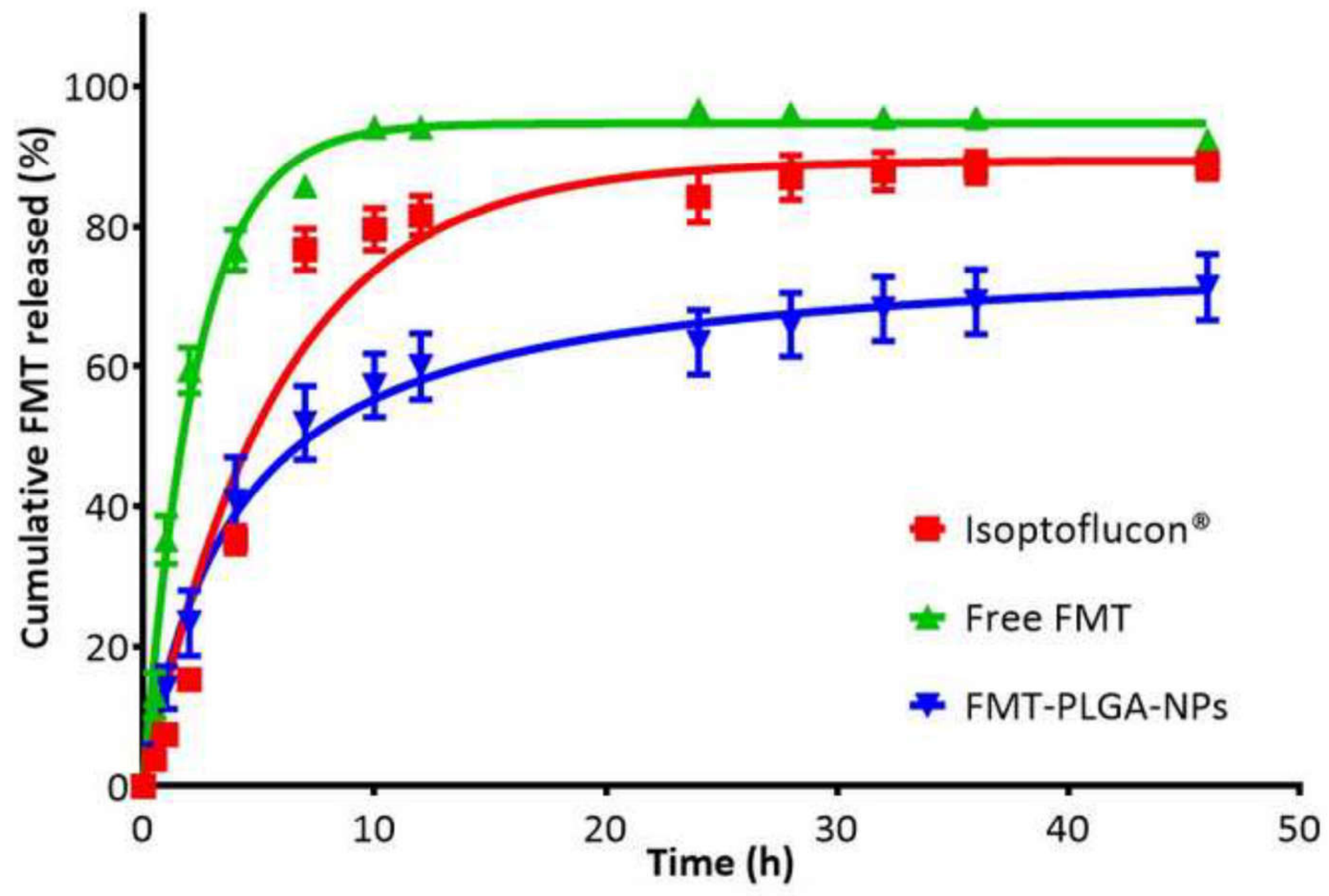




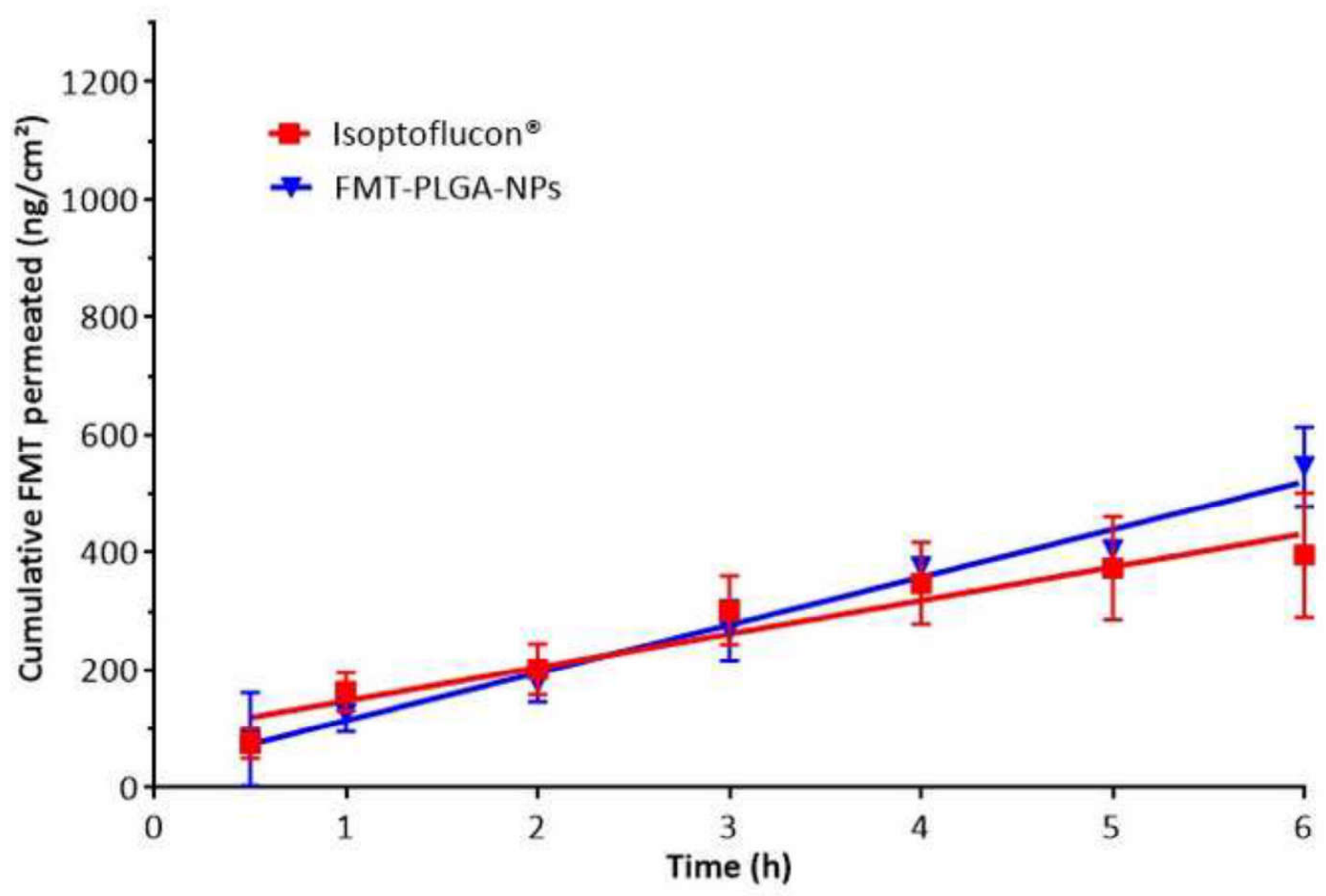

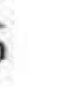




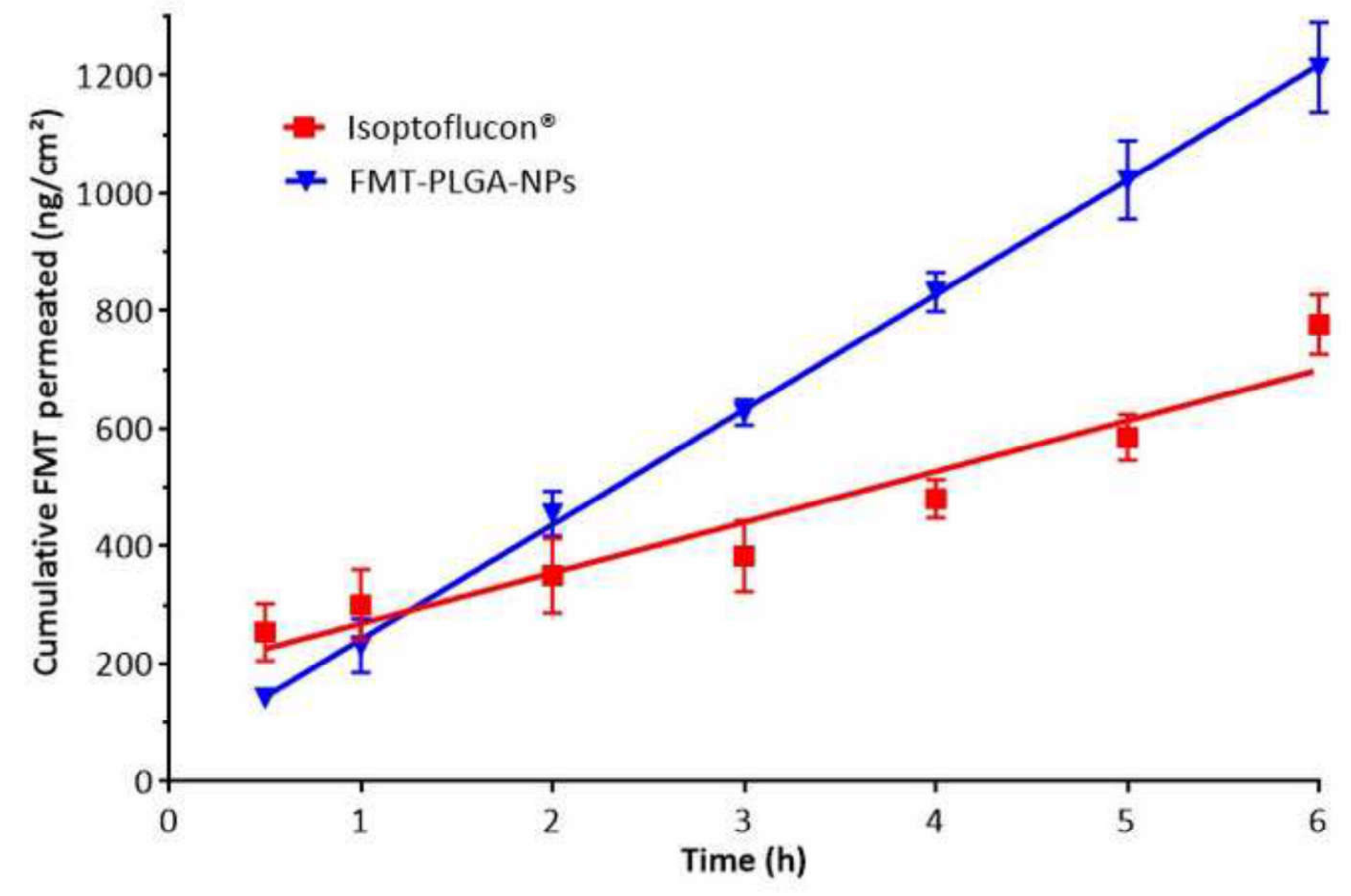




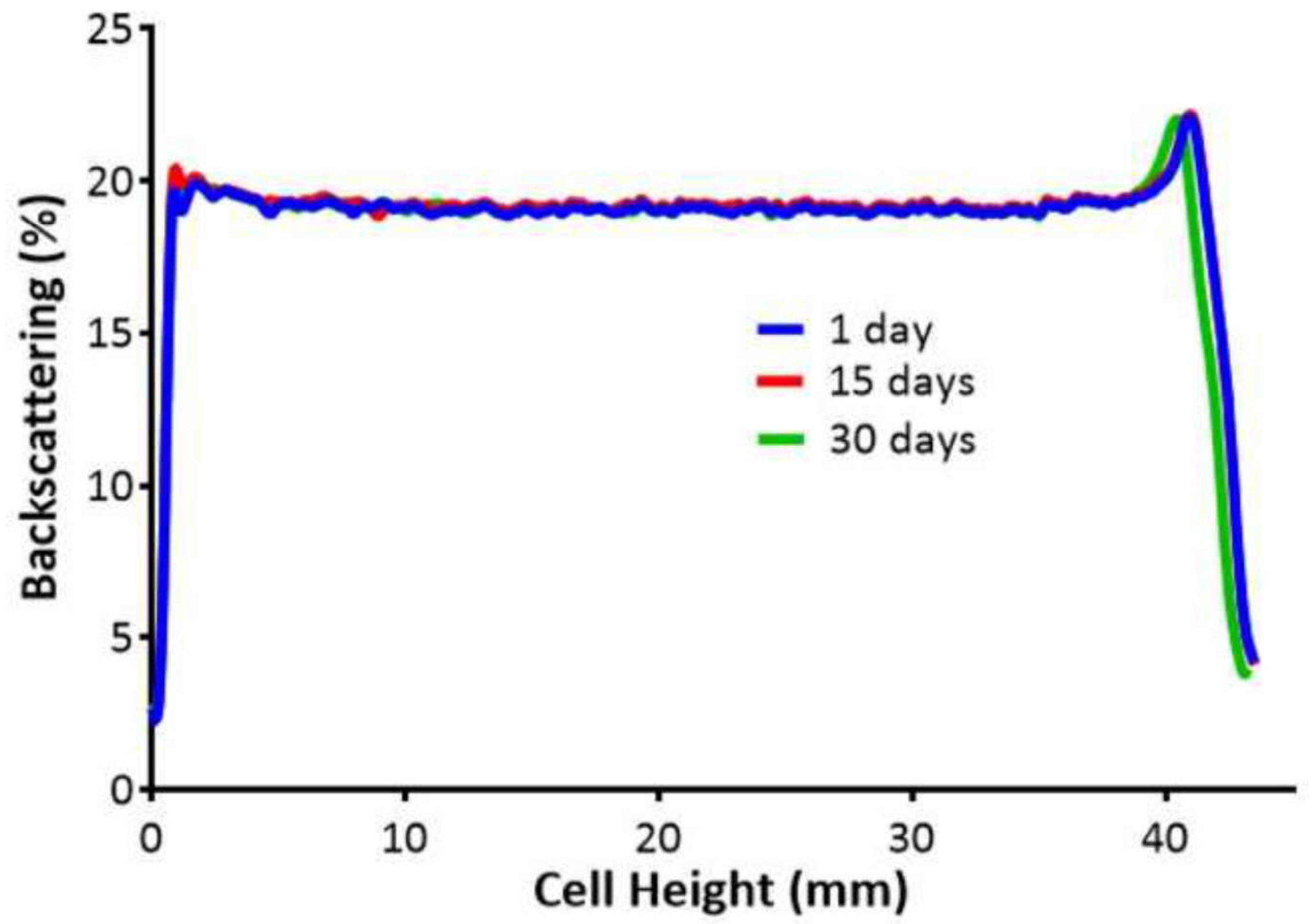




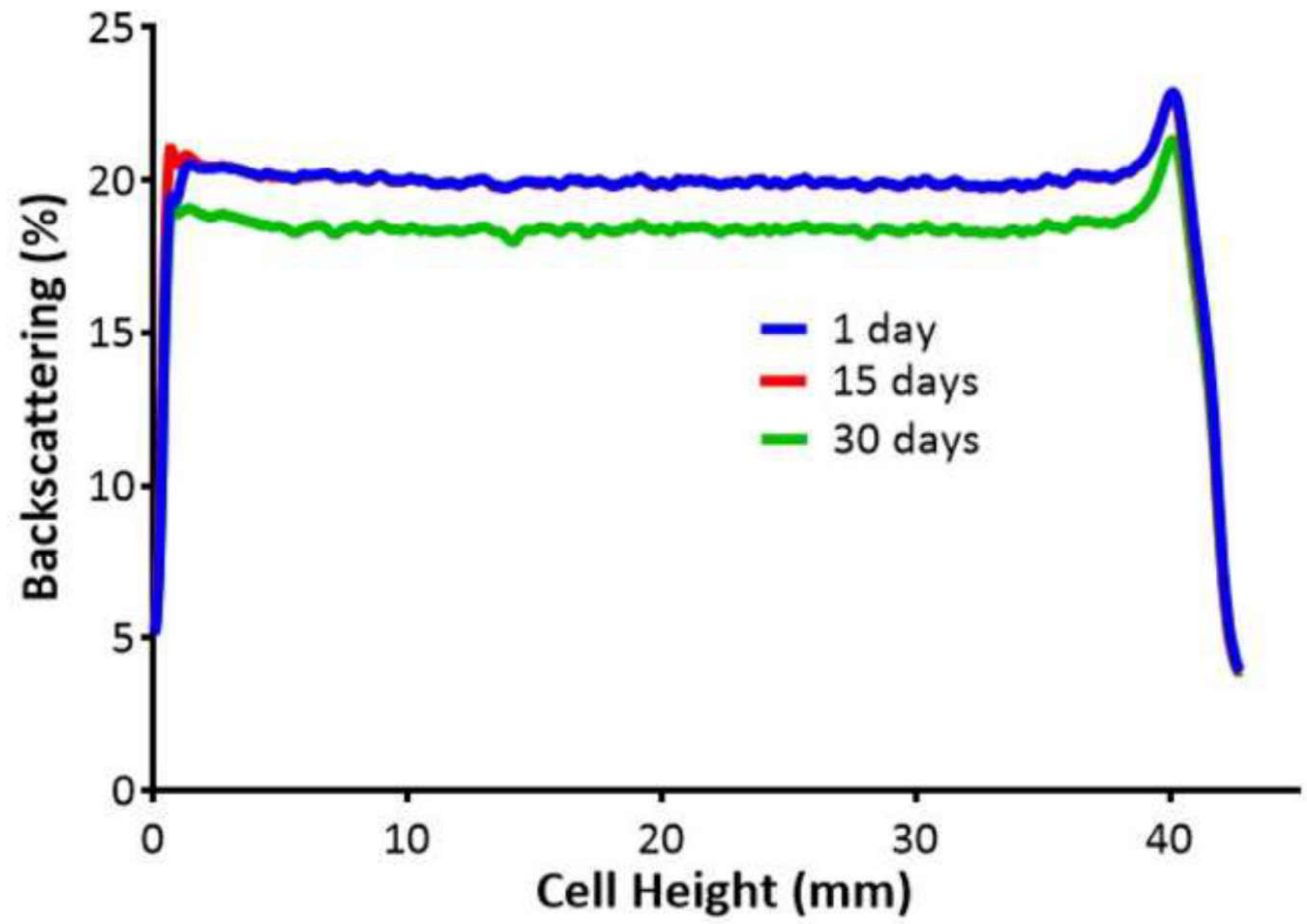




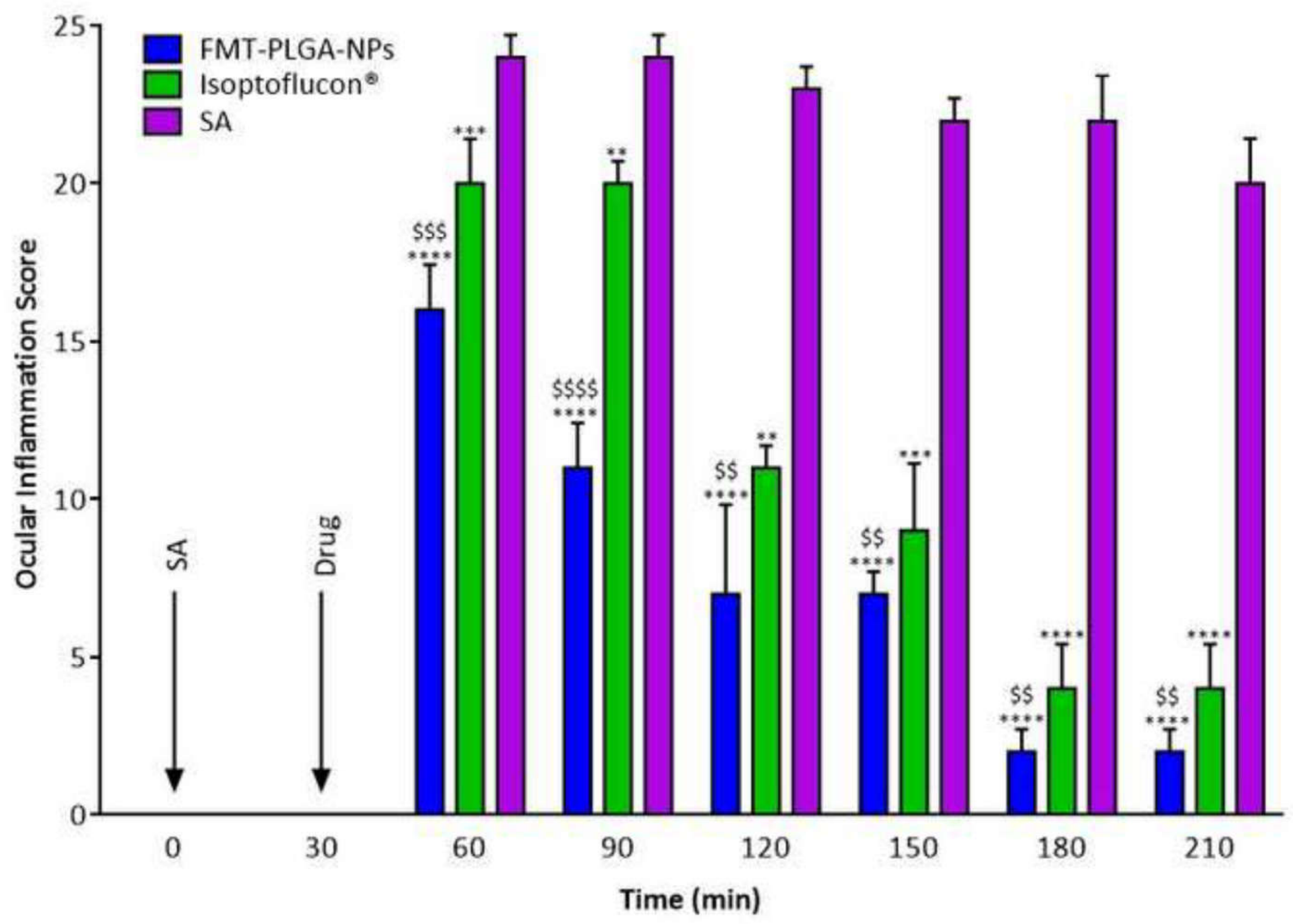


Figure 1. Optimization of the FMT-PLGA-NPs. (a) Zav surface response at a fix $1.5 \mathrm{mg} \cdot \mathrm{mL}^{-1}$ of FMT, (b) Pareto' diagram of the analyzed effect on EE \%.

Figure 2. TEM of FMT-PLGA-NPS

Figure 3. Interactions studies of FMT-PLGA-NPs and NPs components (a) XRD patterns, (b) FTIR spectra, (c) DSC.

Figure 4. In vitro profile release of FMT-PLGA-NPs (adjust to hyperbola equation) against free FMT and Isoptoflucon ${ }^{\circledR}$ (adjust to first order).

Figure 5. Ex vivo permeation profile of FMT-PLGA-NPs compared with Isoptoflucon ${ }^{\circledR}$. (a) Scleral permeation (b) Corneal permeation.

Figure 6. FMT-PLGA-NPs backscattering profile. (a) Storage temperature at $4{ }^{\circ} \mathrm{C}$, (b) Storage temperature at $25^{\circ} \mathrm{C}$.

Figure 7. Comparation of anti-inflammatory efficacy of FMT-PLGA-NPs and Isoptoflucon. Values are expressed as mean $\pm \mathrm{SD} ; * * p<0.01, * * * p<0.001$, and $* * * * p<0.0001$ significantly lower than the inflammatory effect induced by SA; $\$ \$ p<0.01, \$ \$ \$ p<0.001$, and $\$ \$ \$ p<0.0001$ significantly lower than the inflammatory effect induced by Isoptoflucon ${ }^{\circledR}$. 
Supplementary Material
Click here to download Supplementary Material: Supplementary Material.pdf

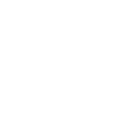

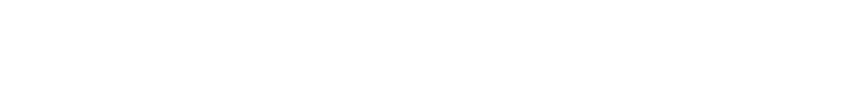

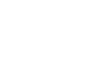

(1)

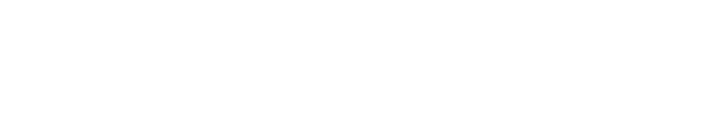
. t

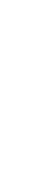
, ,

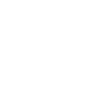
.

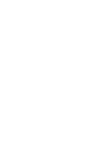
'

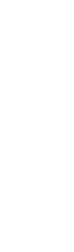
. . . .

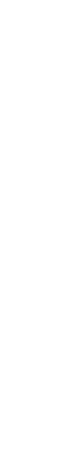

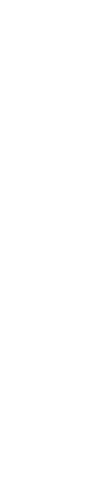
. . 列

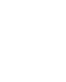

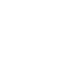

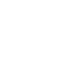

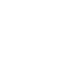

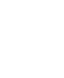
(1) 